\title{
CONDITION OF PRESENT FORESTS
}

\section{By A. BICKERSTAFF}

The most significant development in Canadian forestry during the past ten years is that we are now making a conscious effort to grow forests. Economic, social, and legislative forces are gradually changing a policy of forest liquidation to one of sustained yield forest management. With sustained yield forest management rapidly changing from theory to practice, we must deal with facts - facts about the actual state of our forests - not with unfounded assumptions and wishful thinking.

In particular we must consider those factors which principally influence the technical implementation of long-term forest management policies especially the productivity, age structure, species composition, and quality of the forest, as well as some general consideration of cutting methods.

\section{PRODUCTIVITY}

In long-term planning, the inherent productivity of any area ultimately governs the allowable cut; it governs also the amount of moncy which can be profitably invested in the area for the purpose of growing wood. Forest land -and this its most important characteristic-displays a wide variation in productivity.

While the variation in productivity, both between and within different forest sections, is obvious to the casual observer, the technical implications of this variability are not always recognized. Over large regions - such as the whole of Canada - variation in productivity results chiefly from climate. Growth on the best areas, for instance, may be as much as twenty times that on the poorest areas classed as productive. Because of the distribution of this growth differential, we have a situation where 50 per cent of the total growth potential resides in only 25 per cent of the productive forest area of Canada. Also, within a given climatic region, there is an amazing variation in productivity resulting from the influence of such factors as soil type, soil moisture relationships, and topographic position. In one representative forest section of northern Ontario, these factors cause 65 per cent of the growth potential to be concentrated on only 50 per cent of the productive forest area.

If rational expenditures are to be made for silviculture and for permanent improvemnets to forest areas, they must be directed towards areas of high potential productivity. Under present conditions, for example, no sensible person would advocate a large investment to grow forests in our far northern areas where patches of slow-growing forest alternate with barren land. It is unfortunate that this simple reasoning is not always applied to individual timber limits and management units. On them, present yields are often confused with inherent productivity. Let me put it this way: In Eastern Canada, for example, a poor black spruce site, with a 200-year old stand yielding 20 cords per acre, is often worth more now, than an excellent mixedwood site which supports a 70-year old stand yielding 7 cords of spruce and 28 cords of 
poplar and birch per acre. But for the future, this black spruce site will produce wood fibre at only one-fifth the rate of the mixedwood stand.

If long-term investments in forestry are to "pay off", areas with a high present value before cutting must be separated from those of a low present value but with high growth potential. Should present holdings of forest land be evaluated on the basis of potential productivity, some rather startling changes might be expected in general forest policy.

What then is the present state of productivity in our forests? To answer this we must first define terms.

We must differentiate between the growth which an area can produce, i.e., the growth capacity, and the growth which an area does produce, or the actual current growth. The best index of growth capacity for present Canadian conditions is the mean annual increment at rotation age, that is, the volume of living timber at rotation age, divided by the rotation age. The mean annual increment at rotation age, therefore, represents the amount of wood which can be cut from any area in perpetuity if the yield is harvested only once and at rotation age. For any particular site this is a relatively constant quantity which changes only with the stocking and species composition of the stand.

Growth figures used in this paper as an index of the hidden growth potential of our forests, refer to the mean annual increment for stands of present average stocking. Comparable figures for fully stocked stands would be somewhat higher, but they are largely of theoretical interest since most of our stands are not fully stocked. Moreover, few figures on this are available.

The current annual growth, or the actual amount of wood being produced by a stand at present, is a highly variable quantity, depending chiefly upon the the age of the stand. For any stand, current annual growth starts from zero at the beginning of the rotation, rises rapidly to a maximum, then falls gradually to become a negative value well past rotation age.

When considering either the growth capacity of an area, or its current growth, one must bear in mind the differences between the net growth and the gross growth. The difference between them, resulting from mortality, is often great. The gross growth is approximately one and one-half times to double the net growth. Theoretically, thinnings could salvage the mortality so that the usable growth would be equivalent to the gross growth, rather than the present net growth. All figures quoted here refer to estimated net growth - a more practical concept in the present stage of our forest economy.

Figures on the latent growth, or the mean annual increment at rotation age are very incomplete, but are gradually being improved through growth surveys and inventories by various agencies.

Any estimate of latent growth capacity at this stage must be merely informed guess work. My guess is that the average for Canada is about 20 cubic feet per acre per year for the total productive forest area, all species included. This cover areas where the mean annual growth rangs from a low of 5 cubic feet, to a high of 100 cubic feet, per acre per year. To compare this figure of 20 cubic feet to the estimated depletion figure of 11 cubic feet per acre per 
year on the accessible forests, and to conclude that all is well with our forests is absolute nonsense.

For individual management units the differences between the growth potential, the actual growth, and the amount being cut, are startling. Some units are being hopelessly overcut; in others, the growth potential has hardly been touched. On a broad nationl scale we find that depletion from all sources on occupied forest land amounts to about 22 cubic feet per acre per annum. When one considers that the loss from fire of young unmerchantable stands is not included, and that there is often an abnormally long regeneration period following cutting, there are no grounds for complacency.

\section{Age Class Distribution}

Generalized figures on the age class distribution for all of Canada indicates that, for the country as a whole, we have a reasonably good balance: in our forested area - 56 per cent in merchantable timber, and the remaining 44 per cent in young growth. But for a particular management unit, the poor distribution of age classes resulting from natural causes or present cutting practices is strikingly observable when passing from one part of the country to another. In areas on the east coast of Newfoundland there is no mature timber - and few trees over 7 inches d.b.h. In young stands just approaching their peak current growth, the most vigorous trees are cut as soon as they reach merchantable size. At the opposite extreme we have vast areas in the more northerly parts of Eastern Canada containing overmature stands where the current growth is nil, or even a negative quantity. With present cutting plans these stands will remain untouched for years to come. On limits containing such overmature stands, relatively young stands in the more accessible areas are still being cut, presumably for reasons of economy. Fortunately, such poor cutting practice is diminishing rapidly.

Until age class distributions can be balanced, present actual cuts or allowable cuts will bear little or no relation to the sustained cuts which can obtained on a long-term basis.

There is yet another aspect to the present age class distribution. On many large management units, efforts are being made to bring the overall age class distribution into line. But insufficient efforts are being made to avoid the concentration of one age class in a particular area. This may mean that merchantable timber can be harvested from a particular watershed or compartment only once in a rotation of 60 to 100 years. This concentration in turn, jeopardizes the economic maintenance of permanent improvements, such as roads, which are so necessary for the efficient long-term use and protection of forest areas.

\section{SPECIES COMPOSITION}

The marked change in species following cutting and fire is causing concern in many parts of the country. The trend is for the more valuable softwood species to be replaced by less valuable species - chiefly hardwoods, and these, despite local increases in utilization, are still largely unexploited.

This trend can be changed by sound silvicultural practices, especially where 
the natural cycle is for relatively short-lived intolerant hardwoods to establish themselves after cutting or fire on sites too poor to support them indefinitely. The hardwoods are then gradually invaded and replaced by conifers. Silviculture can speed up this natural cycle by reducing and regeneration period. It also can avoid an increase in the amount of derelict land supporting poor quality hardwood species which prove totally unsuited to the site.

A quite different situation is often encountered on some of our better areas. In these, coniferous species may be established following a severe fire on sites where the natural climax is a hardwood forest. When such coniferous stands are cut they revert, largely, to good quality rapid-growing hardwoods. The re-establishment of conifers on such sites is usually impracticable, both economically and silviculturally.

Hardwood growth makes up about 40 per cent of the total potential increment of our forests, but the depletion of hardwoods amounts to less than 20 per cent of the total depletion. Stated differently, one-half of the overall growth potential for softwood species is now being depleted, but only onefifth of the hardwood growth is being used. The development of economic uses for hardwoods is therefore one of the most direct and practicable means for increasing utilization to balance the growth potential latent in Canadian forests.

\section{WOOD QUALITY}

As with many other natural or manufactured products, high quality wood is relatively scarce and thereby commands a premium, while low grade material is a glut on the market. It is apparent that many forested areas which once provided premium quality wood are now supporting poor quality stands of no present economic value. These stands have been aptly described as "silvicultural slums", and are most evident on sites with a high growth potential, or where a high hardwood component is present. In the absence of improved utilization for low grade material, it is meaningless to speak of silvicultural measures to bring these stands back into useful production.

One aspect of quality production is sometimes overlooked - some of our best material has taken well over 200 years to produce. It is unlikely that such rotations will be economically feasible in the future. It is a fallacy to assume that because we once took high quality material from a given area we can economically produce it there again. The hope for high quality sawlog and veneer production, therefore, lies in the better sites of our most productive climatic regions.

\section{Cutting Methods}

No discussion of the condition of present forests would be complete without some mention of cutting methods. Fortunately this is relatively simple. Clearcutting usuable species either to the lowest diameter limit which can be profitably utilized, or the diameter limit set by provincial regulations, is the most characteristic method east of the Rockies and is applied to all types. The effect of this practice on the regeneration of the new stand has been variable, and will undoubtedly be discussed in one of the subsequent papers. 
Since the end of the war, increasing interest has been shown in developing alternative economic cutting methods. This has been partly to improve regeneration, and partly because of the feeling that "growth" can be increased - in some manner - by partial cutting methods. That usable growth can be increased by partial cutting methods is true-by salvaging some of that wood which would otherwise be lost through mortality. However, partial cutting at its best, is but one step in the direction of better forest management; at its worst, it is a synonym for high-grading.

\section{CONCLUSION}

This paper has attempted to show the influence on management practices of the present productivity, age-class distribution, species composition, and quality of our forests. We must not be misled into believing that there is some short cut, or magic formula such as partial cutting, which will bring about sustained yield management overnight in a simple painless manner. On the contrary, the most efficient long-term use of the fixed growth potential will be made by:

(a) Concentrating effort on the most productive areas;

(b) Ensuring good stocking by regenerating productive areas to species which are suited to the site;

(c) Harvesting stands at a reasonable rotation age;

(d) Utilizing the species and products which the site is best capable of producing;

(e) Utilizing by thinnings, improvement cuts, and partial cutting systems that part of the growth which would otherwise be lost through mortality;

(f) Conducting sufficient research and pilot plant testing to provide practicable answers to the technical problems which will be encountered.

These are the basic requirements for forest management - for management of our forests as they are at present, until they reach the favorable state we can foresee for them. 